\title{
Scientific impact of Iran University of Medical Sciences researchers in ResearchGate, Google Scholar, and Scopus: An altmetrics study
}

\author{
Leila Nemati-Anaraki ${ }^{1}$, Maryam Razmgir ${ }^{1}$, Mina Moradzadeh*1,2 (1)
}

Received: 13 Jan 2019

Published: 22 Oct 2020

\section{Abstract}

Background: The emergence of web 2.0 and development of social media have strongly affected sharing, collaborating, connecting, and evaluating in academic setting. This study aimed to provide a clear image of faculty members' activities at Iran University of Medical Sciences (IUMS) and the way they communicate with the academic world in ResearchGate (RG).

Methods: In this altmetrics study, we surveyed the presence and activity of IUMS faculty members in RG and compared the data with those derived from Google Scholar and Scopus. The Spearman's correlation coefficient was used to detect the correlation between RG variables and the 2 mentioned databases. The significance level was set at $\alpha=0.01$. Data were statistically analyzed using the Microsoft Excel 2013 and SPSS 22.0 software.

Results: The results demonstrated 439 (45\%) faculty members of IUMS had RG profiles, and the School of Medicine with 287 researchers had the largest contribution. Overall, 14971 documents were shared, $91 \%$ of which were journal articles. The average RG score was $15.26 \pm 9.28$, of which $94 \%$ was acquired from publications. This indicates a positive and strong correlation between RG variables and Scopus and Google Scholar indicators, while the RG indicators were more correlated with Google Scholar than Scopus.

Conclusion: Due to the essential role of self-archiving in the visibility, citation rate, and creation of further international collaborations, it is recommended that Iranian scholars consider using the Academic Social Networks like RG to enhance their online international contributions.

Keywords: ResearchGate, RG, Google Scholar, Scopus, Academic Social Networks, ASNs, Academic Contribution, Altmetrics, Iran, Iran University of Medical Sciences, IUMS

Conflicts of Interest: None declared

Funding: This study was funded by Iran University of Medical Sciences (IUMS), Tehran, Iran; Grant Number: IUMS/SHMIS-97-01-136-31955.

*This work has been published under CC BY-NC-SA 1.0 license.

Copyright $\odot$ Iran University of Medical Sciences

Cite this article as: Nemati-Anaraki L, Razmgir M, Moradzadeh M. Scientific impact of Iran University of Medical Sciences researchers in ResearchGate, Google Scholar, and Scopus: An altmetrics study. Med J Islam Repub Iran. 2020 (22 Oct);34:142. https://doi.org/10.47176/mjiri.34.142

Introduction

Number of citations, highly cited papers, and researchers are the main indicators to evaluate the universities in rank-
Corresponding author: Mina Moradzadeh, moradzadeh.mina@iums.ac.ir

1. Department of Medical Librarianship and Information Sciences, School of Health Management and Information Sciences, Iran University of Medical Sciences, Tehran, Iran

2. Health Services Management Research Center, Institute for Futures Studies in Health, Kerman University of Medical Sciences, Kerman, Iran $\uparrow$ What is "already known" in this topic:

Web 2.0 and the development of Academic Social Networks (ASNs) have changed the means of sharing, collaborating, and connecting among scholars. Followed by ASNs, altmetrics indicators have served as complementary measures of traditional metrics to evaluate researchers' impact. Therefore, academic institutes can enhance international collaboration, absorb more citations, and finally develop university ranking by encouraging their researchers to join ASNs such as ResearchGate.

$\rightarrow$ What this article adds:

Nearly half of Iran University of Medical Sciences (IUMS) faculty members have a ResearchGate (RG) profile and have obtained $97 \%$ of the RG score. The scientific interaction of IUMS researchers in RG was weak, as $94 \%$ of the RG score was acquired from publications, not Question and Answer (Q \& A) and followers. The RG indicators were correlated more with Google Scholar than Scopus. 
ing systems (1). Publishing research findings in the internet-centric society, presenting research to the target community, and providing more visibility are the major challenges of researchers and universities. The research impact has traditionally been assessed by bibliometric measures like H-index $(2,3)$ and Impact Factor (IF), both of which refer to the numbers of publications and citations received $(4,5)$.

However, the traditional metrics are not able to measure the complete research impacts evolved by the emergence of web 2.0 and the social media tools in 2004. Social media has strongly impacted sharing, collaborating, and connecting in academic worlds $(6,7)$, and it has become the major collaborative tool in content sharing and academic communication of the research life-cycle in recent years $(8,9)$. In these platforms, the research outputs could be visible more rapidly and conveniently. Thus, the social networks' interactions and activities serve as complementary measures for researcher evaluation with the traditional methods (10).

In 2010, "Altmetrics", as a new research impact metrics, emerged along with the modern academic publishing environment. This metric can provide new insights into academic communications and track the online media attention of research results $(11,12)$.

Facebook was the primary social media, which was used to share academic papers and maintain connection between researchers (13) and followed by introducing the Academic Social Networks (ASNs), which are scientific social media essentially developed for disseminating research works and communications among scholars. ResearchGate (RG), Academia, LinkedIn, Twitter, and Mendeley are the most popular ASNs (14).

LinkedIn was launched in 2003 with a focus on a professional network of contacts, business, and work related jobs (15). Twitter was initiated in 2006 , operating as a social network and a powerful news media (16). Academia was founded as a platform for sharing research papers in 2007 (17), and it developed a list of publication options later for the research community in 2013 (18). Mendeley, an online reference manager which serves as an ASN, was introduced in 2008 (19). RG, as a professional academic network for researchers, was developed by Ijad Madisch in 2008. This academic network with over 15 million users has mainly concentrated on sharing scientific publications and communications in research networks (20).

ASNs provide potential sources for a large collection of publicity shared preprints, post prints, and all document types (21). It helps academic institutes to enhance international collaboration, absorb more citations, and eventually contribute to university ranking by encouraging their researchers to join ASNs like RG. The number of reads, followers, and share of contributions are the main items to consider by RG in ranking researchers and academic institutions.

The presence and activity of researchers in RG has been studied and evaluated in many countries and universities worldwide (22-29). Similarly, evidence of research activities in Iran has been recently evaluated and reported. Erfanmanesh et al examined the contribution of Iranian universities and research institutions in RG and showed a positive and weak correlation between uploading papers in RG and receiving citations (30). Examining the presence of the library and information science scholars of Ahvaz universities, including Islamic Azad University Ahvaz Branch, Ahvaz University of Medical Sciences, and Shahid Chamran University of Ahvaz in RG, Asnafi et al found that most faculty members had a profile in RG; however, the authors of Islamic Azad University Ahvaz Branch had more contributions (31). Khalili performed a study on the participation of Iranian medical universities in $\mathrm{RG}$ and showed that the high-ranking universities were more active in RG and Tehran University of Medical Sciences had the strongest coauthorship network among Iranian medical universities (32). Siamaki et al focused on the activity of Isfahan University of Medical Sciences' researchers in RG, and found that scholars of Isfahan University of Medical Sciences had a low contribution in $\mathrm{RG}$ despite being one of the major universities in Iran with a great number of researchers (33). Asnafi reviewed the participation of faculty members of Shahid Beheshti University in RG. Their findings indicated that disciplines of chemistry, laser, plasma, and physics had the utmost presence in RG. In contrast, the humanities discipline did not have any activities (34). Naderbeigi and Esfandyari-Moghadam investigated the performance of the faculty members of "Technology University" in RG. The results showed most of faculty members were active in $R G$, affecting their citations and $\mathrm{H}$-index (35).

With this background and to the best of our knowledge, there was no evidence on the performance of Iran University of Medical Sciences (IUMS) researchers in RG. Thus, in this study we investigated the contribution of IUMS faculty members in RG, compared with their Google Scholar and Scopus citation indicators.

\section{Methods}

This altmetrics study was conducted to evaluate the scientific impact of IUMS faculty members in RG, Scopus, and Google Scholar. To collect data, we searched the complete name of the university, "Iran University of Medical Sciences", as an institution in RG to identify the IUMS researchers who had a profile in RG. To extract the faculty members from the entire list of researchers, the results were compared with the list of IUMS faculty members. We manually revised the incorrect data and added the missing ones. IUMS had 964 faculty members at the time of study (October 2018), of whom 438 had RG profile.

The RG indicators, including research items, number of reads, citations, $\mathrm{RG}$ score, percentile, and $\mathrm{H}$-index, were manually extracted from RG. The demographic data, containing school name, institution, degree, gender, and the bibliometric data, such as number of Scopus and Google Scholar papers, citations, and $\mathrm{H}$-index were extracted from the Iranian Scientometric Information Database (ISID: http://isid.research.ac.ir/), Scopus, and Google Scholar databases. The analysis was conducted manually by Microsoft Excel 2013 software and the descriptive statistics, such as frequency, mean, and standard deviation of variables, were used to report the general characteristics of the population.

Since the data were not normal, Spearman's correlation 
coefficient was performed to determine the relationship between RG variables and Scopus and Google Scholar indicators. The significance level was set at $\alpha=0.01$ and the analysis was conducted by SPSS 22.0 software.

\section{Results}

Overall, 1276 researchers were affiliated with IUMS in RG until October 2018. Out of 1276 , a total of 439 researchers (34\%) were IUMS faculty members and 837 $(66 \%)$ were students and other researchers. At the time of the study, the total number of IUMS faculty members was 964, of whom $439(45 \%)$ had RG profile. In addition, 250 out of $439(57 \%)$ were male and $189(43 \%)$ female (Table 1).

A total of 439 faculty members were affiliated to 21 IUMS schools and institutions with different positions/degrees. Most of the faculty members (93\%) who were affiliated to IUMS schools and the research centers appeared to have less participation (7\%). The School of Medicine with 287 researchers had the largest contribution and was placed first, followed by the School of Rehabilitation Sciences and
School of Public Health, respectively. Figure 1 demonstrates the presence of IUMS faculty members across the schools and research centers in RG. There were 226 (52\%) assistant professors, $119(27 \%)$ associate professors, 80 $(18 \%)$ professors, and $14(3 \%)$ lecturers.

\section{ResearchGate Results}

Table 2 indicates 13 out of 439 (3\%) IUMS faculty members have zero items on their RG profiles; therefore, the "read" and related indicators of RG could not be calculated for them. The other 426 members shared at least 1 publication, while $6.4 \%$ had more than 100 research items.

The results suggest the IUMS faculty members shared 14 971 documents on RG, 13589 of which (91\%) were journal articles and 1382 (9\%) other types of publications, including data, theses, conference papers, presentations, posters, patents, book chapters, experimental findings, and preprints. They have provided the full-text of 8565 out of 13 $589(63 \%)$ journal articles. The publications have received 112886 citations in RG.

Table 1. Iran University of Medical Sciences faculty members gender distribution in ResearchGate

\begin{tabular}{llccc}
\hline Gender & \multicolumn{2}{c}{ IUMS Faculty Members } & \multicolumn{2}{c}{ IUMS Faculty Members in RG } \\
\cline { 2 - 5 } & No & $\%$ & No & $\%$ \\
Female & 419 & 43.5 & 189 & 43.0 \\
Male & 545 & 56.5 & 250 & 57.0 \\
Total & 964 & 100.0 & 439 & 100.0 \\
\hline
\end{tabular}

Abbreviations; IUMS: Iran University of Medical Sciences; RG: ResearchGate.

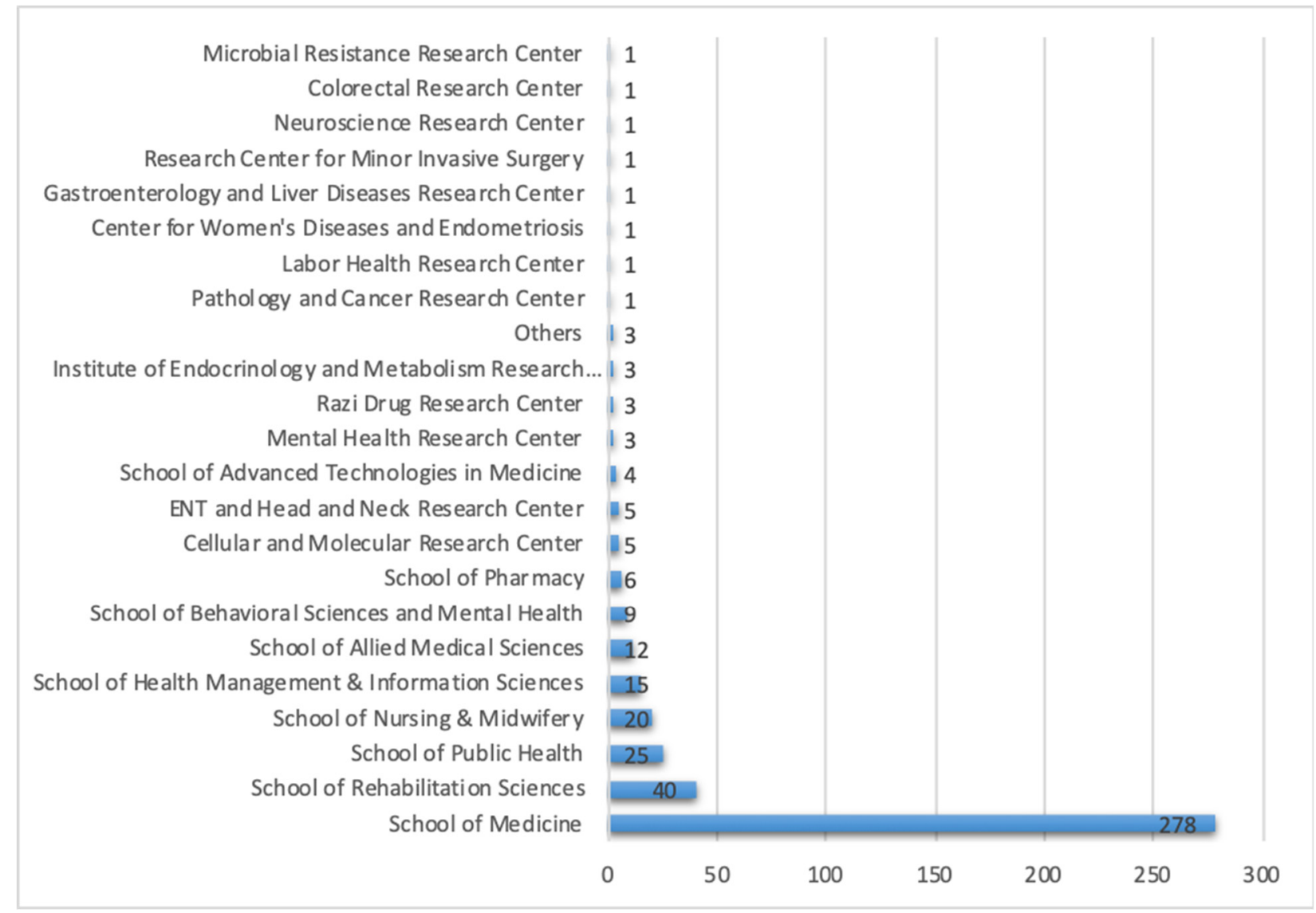

Fig. 1. Iran University of Medical Sciences faculty member ResearchGate profile distribution over schools and research centers 


\begin{tabular}{ccc} 
Table 2. Number of Iran University of Medical Sciences faculty members' research items in ResearchGate & \\
\hline No of Research Items & No of Faculty Members & \% of Faculty Members \\
\hline 0 & 13 & 3 \\
$1-20$ & 192 & 43.7 \\
$21-40$ & 115 & 26.2 \\
$41-60$ & 54 & 12.3 \\
$61-80$ & 25 & 5.7 \\
$81-100$ & 12 & 2.7 \\
$>100$ & 28 & 6.4 \\
Total & 439 & 100 \\
\hline
\end{tabular}

Abbreviations; No: Number

The average RG score of IUMS researchers was $15.26 \pm 9.28$, and 10502.69 of the $10795.98 \mathrm{RG}$ scores $(97 \%)$ were obtained by the IUMS faculty members. The $\mathrm{RG}$ score is calculated based on number of research items, followers, and Q\&A; our findings showed that $94 \%$ of the IUMS RG score was acquired from research items and the portion of Q\&A and followers were 6\%. The average RG percentile of IUMS faculty members was $54.35 \pm 25.35$ and the average RG H-index was $6.16 \pm 4.76$.

\section{Collaboration in ResearchGate}

The researchers from Iran, United States, and India showed greater tendency in reading the publications of IUMS researchers. The highest collaboration with IUMS researchers belonged to Tehran University of Medical Sciences (TUMS) and Shahid Beheshti University of Medical Sciences (SBUMS).

Spearman's correlation coefficient was computed to assess the relationship between the RG indicators (Table 3). The RG score of IUMS faculty members had a positive and strong correlation with the number of journal articles $(\mathrm{r}=0.906, \mathrm{p}<0.001)$ and the full-text $(\mathrm{r}=0.792, \mathrm{p}<0.001)$.
However, the RG score had no correlation with questions $(\mathrm{r}=-0.804, \mathrm{p}=0.080)$ and followers $(\mathrm{r}=-0.004, \mathrm{p}=0.937)$; and its correlation with answers was moderate $(\mathrm{r}=0.201$, $\mathrm{p}<0.001)$. The highest correlation of the RG score was with the number of journal articles, H-index, citations, and reads, respectively.

\section{ResearchGate indicators versus Scopus and Google} Scholar

Overall, IUMS faculty members have published 24418 scientific documents in Google Scholar and 10756 in Scopus. However, they have shared only 14797 items in their RG profiles. Moreover, 7 of 439 members had no Scopus profile and 33 had no Google Scholar profile. The average $\mathrm{H}$-index of IUMS faculty members in Google Scholar was greater than RG and Scopus; however, the citation per document in Scopus was higher than the other 2 databases. Table 4 presents the IUMS faculty members' citation indicators in RG, Google Scholar, and Scopus.

Based on Spearman's correlation coefficient, a positive and strong correlation existed between citations and $\mathrm{H}$-index in all 3 databases (Table 5).

Table 3. Spearman's correlation coefficient between ResearchGate indicators of Iran University of Medical Sciences faculty members

\begin{tabular}{|c|c|c|c|c|c|c|c|c|c|c|}
\hline & & 1 & 2 & 3 & 4 & 5 & 6 & 7 & 8 & 9 \\
\hline 1 & RG Score & 1 & $0.906^{*}$ & -0.084 & $0.201 *$ & -0.004 & $0.792^{*}$ & $0.843^{*}$ & $0.887^{*}$ & $0.892 *$ \\
\hline 2 & RG Journal Articles & & 1 & 0.071 & $0.178 *$ & 0.122 & $0.920 *$ & $0.872 *$ & $0.829 *$ & $0.859 *$ \\
\hline 3 & Question & & & 1 & $0.510^{*}$ & $0.175^{*}$ & 0.107 & 0.123 & 0.049 & 0.074 \\
\hline 4 & Answers & & & & 1 & $0.132 *$ & $0.191 *$ & $0.202 *$ & $0.133^{*}$ & $0.144^{*}$ \\
\hline 5 & Followers & & & & & 1 & $0.211 *$ & $0.220 *$ & $0.108^{*}$ & 0.111 \\
\hline 6 & Full text & & & & & & 1 & $0.850 *$ & $0.730 *$ & $0.765^{*}$ \\
\hline 7 & Reads & & & & & & & 1 & $0.826^{*}$ & $0.824^{*}$ \\
\hline 8 & Citations & & & & & & & & 1 & $0.956^{*}$ \\
\hline 9 & H-index & & & & & & & & & 1 \\
\hline
\end{tabular}

Abbreviations; RG: ResearchGate

* Correlation is significant at the 0.01 level (2-tailed).

Table 4. Iran University of Medical Sciences faculty members' citation indicators in ResearchGate, Google Scholar, and Scopus

\begin{tabular}{lcccccr}
\hline Database & No of Profiles & No of Doc & \multicolumn{2}{c}{ H-index } & \multicolumn{2}{c}{ Total Citations } \\
\cline { 4 - 5 } & & & Mean & SD & & \\
\hline RG & 439 & 14797 & 6.16 & 4.76 & 112886 & 7.62 \\
Google Scholar & 403 & 24418 & 7.81 & 6.08 & 188004 & 7.69 \\
Scopus & 432 & 10756 & 5.93 & 4.73 & 103882 & 9.65 \\
\hline
\end{tabular}

Abbreviations; RG: ResearchGate; No: Number; Doc: Documents; SD: Standard Deviations.

Table 5. Spearman's correlation coefficient between H-index and citation in ResearchGate, Google Scholar, and Scopus

\begin{tabular}{|c|c|c|c|c|c|c|c|}
\hline & & 1 & 2 & 3 & 4 & 5 & 6 \\
\hline 1 & RG Citations & 1 & $0.752 *$ & $0.822 *$ & - & - & - \\
\hline 2 & Google Scholar Citations & & 1 & $0.796^{*}$ & - & - & - \\
\hline 3 & Scopus Citations & & & 1 & - & - & - \\
\hline 4 & RG H-index & & & & 1 & $0.727 *$ & $0.820 *$ \\
\hline 5 & Google Scholar H-index & & & & & 1 & $0.781 *$ \\
\hline 6 & Scopus H-index & & & & & & 1 \\
\hline
\end{tabular}

Abbreviations; RG: ResearchGate

* Correlation is significant at 0.01 level (2-tailed). 


\section{Discussion}

Scholarly communication has been transformed from traditional publishing, conference presentations, and face-toface scientific contribution to ASNs $(36,37)$. ASNs provide an opportunity to improve the international scientific collaboration and can promote the visibility and impact (38). A significant number of researchers around the world use ASNs for academic development. Thus, researchers are required to adapt themselves with the newly emerging social media (39).

$\mathrm{RG}$ is an ASN platform that has changed the method of academic networks as it allows researchers to share their publications and connect with peer scientists all over the globe. Over 15 million researchers used RG at the time of the study. Accordingly, we surveyed the status of IUMS faculty members' activities in RG and compared the data with Google Scholar and Scopus indicators.

Results showed 1276 IUMS researchers had a profile in RG. Comparing our findings with Erfanmanesh's study that surveyed the status of Iranian universities in RG in 2015, showed the number of IUMS researchers in RG increased by nearly 7 times, the number of publications tripled, and the RG score increased 6 times from 2015 to 2018 (30).

Overall, only $34 \%$ of IUMS researchers in RG were faculty members and they gained $97 \%$ of the RG score. In other words, although the presence of IUMS faculty members was less than other researchers, their scientific contribution was significant and they were identified as active members.

In another view, IUMS had 964 faculty members at the time of the study and nearly half of them had a RG profile. Compared with Naderbeigi's report (35), in which $75 \%$ of Sharif University of Technology (SUT) faculty members had a profile in RG, it can be inferred IUMS faculty members should contribute more.

Other findings revealed $94 \%$ of the RG score was acquired from sharing publications and there was a positive and strong correlation between RG score and the number of journal articles and full-texts. However, no correlation was found between RG score and Q \& A and followers. This is consistent with Naderbeigi's findings (35) and is in contradiction with those of Orduna-Malea et al (40). Since the biggest portion of scores comes from publications, this may be due to weak international collaboration, indicating that academic interactions did not have a significant role in acquiring IUMS RG score. Therefore, it is recommended Iranian authors further consider using ASNs like RG to promote their international collaboration, as the self-archiving of the research outputs plays an essential role in increasing the visibility and citation rate (38).

The paper per researcher in this study was 1.5 , which is comparable to those found by Khalili, which was reported 2.5 in Iran (32). Based on reports by Thelwall and Kousha, the number of documents per researcher is low in Iran (13); indicating Iranian researchers play a symbolic role in $\mathrm{RG}$ and they join ANSs to gain access to the full-text of papers like a repository, not for scientific collaborations. Low familiarity with ASNs features, their capability, and little trust for disseminating academic works and ideas, which have originated from Iranian dominant cultures, are the major factors contributing to the current situation (41).

Whereas IUMS faculty members did not upload all of their publications in their RG profiles, the $R G$ indicators was dependent on available data, and the paper coverage, number of citations, and $\mathrm{H}$-index in RG were correlated with Google Scholar. The indicators were lower than Google Scholar and higher in Scopus, which is consistent with previous findings $(21,35,42)$.

\section{Study limitations}

Three limitations in this study should be noted. First, some researchers did not determine their academic positions in their RG profiles; therefore, to find the IUMS faculty members among other IUMS researchers, we matched the extracted results with the IUMS faculty members list. Second, some IUMS faculty members did not add their affiliations to their RG profiles and we could not find them by searching in RG. To find them, we matched the list of faculty members with the RG results then searched the missing ones manually in RG once more. Third, some scholars did not add all of their publications in the RG profile and we could not address this missing information.

\section{Conclusion}

New indicators of ASNs are at the beginning stages of development and in a near future they will be considered as a complementary measure, along with the other conventional indicators, to measure the scientific impact of researchers. According to the findings of the present study, less than half of IUMS faculty members had RG profiles to communicate with their academic peers; thus, an approach is required to improve the current status. To increase the international collaboration and impact of Iranian scholars in the research world and ASNs, we suggest universities develop some programs or workshops to introduce new ASNs and their benefits for scholars and encourage them to collaborate more with the academic world.

\section{Ethical issues}

This paper is based on the research which was reviewed and approved by the School of Health Management and Information Sciences, Iran University of Medical Sciences (IUMS), Tehran, Iran; Ethical number: IR.IUMS.REC.1397.141.

\section{Conflict of Interests}

The authors declare that they have no competing interests.

\section{References}

1. Ghane MR, Khosrowjerdi M, Azizkhani Z. The ranking of Iranian universities based on an improved technique. Malays J Libr Inf Sci. 2013;18(2):33-45.

2. Garfield E, Sher IH. New factors in the evaluation of scientific literature through citation indexing. Am Doc. 1963;14(3):195-201.

3. Hirsch JE. An index to quantify an individual's scientific research output. Proc Natl Acad Sci USA. 2005;102(46):16569-72.

4. Ajiferuke I, Wolfram D. Citer analysis as a measure of research impact: library and information science as a case study. Scientometrics. 2010;3(83):623-38 
5. Colaco M, Svider PF, Mauro KM, Eloy JA, Jackson-Rosario I. Is There a Relationship between National Institutes of Health Funding and Research Impact on Academic Urology? J Urol. 2013;190(3):9991003

6. Giglia E. Academic social networks: It's time to change the way we do research. Eur J Phys Rehabil Med. 2011;47(2):345-9.

7. Tim O. What is web 2.0: Design patterns and business models for the next generation of software2005 [cited December 2018. Available from: http://www.oreilly.com/.

8. Asur S, Huberman BA, editors. Predicting the future with social media. Proceedings of the 2010 IEEE/WIC/ACM International Conference on Web Intelligence and Intelligent Agent Technology - Volume 012010 ; Washington, DC, USA: IEEE Computer Society.

9. Rowlands I, Nicholas D, Russell B, Canty N, Watkinson A. Social media use in the research workflow. Learn Publ. 2011;24(3):183-95.

10. Galligan F, Dyas-Correia S. Altmetrics: Rethinking the way we measure. Ser Rev. 2013;39(1):56-61.

11. Wooldridge J, King MB. Altmetric scores: An early indicator of research impact. J Assoc Inf Sci Technol. 2019;70(3):271-82.

12. Barnes C. The Use of Altmetrics as a Tool for Measuring Research Impact. Aust Acad Res Libr. 2015;46(2):121-34.

13. Thelwall M, Kousha K. ResearchGate: Disseminating, communicating, and measuring scholarship? J Assoc Inf Sci Technol. 2015;66(5):876-89.

14. Ovadia S. ResearchGate and Academia. edu: Academic social networks. Behav Soc Sci Librar. 2014;33(3):165-9.

15. Wilson J. Social networking: the business case-[IT internet]. Eng Technol. 2009;4(10):54-6.

16. Kwak H, Lee C, Park H, Moon S, editors. What is Twitter, a social network or a news media? Proceedings of the 19th international conference on World wide web; 2010: AcM.

17. Mangan K. Social networks for academics proliferate, despite some doubts. Chron High Educ. 2012;58(35):1-7.

18. Thelwall M, Kousha K. Academia.edu: Social network or academic network? J Assoc Inf Sci Technol. 2014;65(4):721-31

19. Li X, Thelwall M, Giustini D. Validating online reference managers for scholarly impact measurement. Scientometrics. 2011;91(2):461-71.

20. Researchgate is built by scientists, for scientists 2017 . available via: https://wwwresearchgatenet/about. 2018.

21. Thelwall M, Kousha K. ResearchGate versus Google Scholar: Which finds more early citations? Scientometrics. 2017;112(2):1125-31.

22. Borrego Á. Institutional repositories versus ResearchGate: The depositing habits of Spanish researchers. Learn Publ. 2017;30(3):18592.

23. Iglesias-García M, González-Díaz C, Codina L. A study of student and university teaching staff presence on ResearchGate and Academia.edu in Spain. Media and Metamedia Management: Springer; 2017. p. 509-15.

24. Jeyapragash B, Rajkumar T, Muthuraj A. Research contributions of Indian universities in ResearchGate: An analysis. J Adv Model Earth Syst. 2018;7(1):1-6

25. Míguez-González MI, Puentes-Rivera I, Dafonte-Gómez A. Academic social networks and communication researchers from universities in the North of Portugal: An analysis of Academia.edu and ResearchGate. Media and Metamedia Management: Springer; 2017.p. 405-11.

26. Shrivastava R, Mahajan P. Relationship amongst ResearchGate Altmetric indicators and Scopus bibliometric indicators: The case of Panjab University Chandigarh (India). New Libr World. 2015;116(9/10):564-77.

27. Shrivastava R, Mahajan P. An altmetric analysis of ResearchGate profiles of physics researchers: a study of University of Delhi (India). Perform Meas Metr. 2017;18(1):52-66.

28. Singson M, Amees M. Use of ResearchGate by the research scholars of Pondicherry university: A study. DESIDOC J Libr Inf Tech. 2017;37(5):366-71.

29. Verma S, Margam M. A study of ResearchGate profiles of the medical science department of University of Delhi: An Altmetric perspective. Digital Transformation Strategies and Trends in E-Learning: Privacy, Preservation and Policy: Segment Books; 2018. p. 951-66.

30. Erfanmanesh M, Asnafi A, arshadi h. Iranian universities and research institutions in the ResearchGate: An altmetric study. Sci J Manag Syst. 2015;8(30):59-72 [In Persian].

31. Asnafi AR, Salami M, Sayyah Baragar M, Hosseini Ahangari SA. Presence of Ahavz universities (Medical Science, Azad and
Governmental) scholars Iranian library and information science scholars in academic social network: ResearchGate. Educ Dev Jundishapur. 2015;6(1):67-73 [In Persian].

32. Khalili L. Participation of Iranian medical universities in Researchgate. Health Inf Manage. 2016;13(4):273-9 [In Persian].

33. Siamaki S, Geraei E, Zare FF. A survey on the presence of Isfahan University of Medical Sciences researchers in ResearchGate network: An Altmetrics study. Health Inf Manage. 2016;13(5):341-6 [In Persian].

34. Asnafi AR. Reviewing Shahid Beheshti University scholars' presence in ResearchGate. Hum Inf Interact. 2016;2(3):61-70 [In Persian].

35. Naderbeigi F, Isfandyari-Moghaddam A. Researchers' Scientific performance in ResearchGate: The Case of a Technology University. Libr Philos Pract. 2018:1-18.

36. Arshad A, Ameen K. Scholarly communication in the age of Google: Exploring academics' use patterns of e-journals at the University of the Punjab. Electron Libr. 2017;35(1):167-84.

37. Liu Z. Trends in transforming scholarly communication and their implications. Inf Process Manag. 2003;39(6):889-98.

38. Harnad S. Publish or perish — self-archive to flourish: The green route to open access. ERCIM News. 2006;64.

39. Asnafi AR, Erfanmanesh MA, Pakdaman Naeini M. Presence of the Iranian library and the information science departments in ResearchGate. DESIDOC J Libr Inf Tech. 2017;37(4).

40. Orduna-Malea E, Martín-Martín A, Thelwall M, López-Cózar ED. Do ResearchGate Scores create ghost academic reputations? Scientometrics. 2017;112(1):443-60.

41. Bayat M, Schøtt T, Zali MR. Firms' collaboration networks benefitting innovation: embeddedness in high-and low-trust culture, Denmark and Iran. Int J Entrepreneurship Small Bus. 2014;23(12):168-90.

42. Martín-Martín A, Orduña-Malea E, Ayllón JM, López-Cózar ED. The counting house: Measuring those who count. Presence of bibliometrics, scientometrics, informetrics, webometrics and altmetrics in the Google Scholar citations, Researcherid, ResearchGate, Mendeley \& Twitter. arXiv preprint arXiv:160202412. 2016. 